\title{
COMPORTAMENTO DOS PREÇOS HISTÓRICOS DO LEITE NO RIO GRANDE DO SUL, BRASIL
}

\author{
Behavior of historical prices of milk in Rio Grande do Sul, Brazil
}

\author{
João Garibaldi Almeida Viana', Bárbara Zen², Fábio Karlec², Renato Santos de Souza²
}

\begin{abstract}
RESUMO
Neste trabalho, objetivou-se analisar o comportamento de tendência, sazonalidade e ciclos dos preços reais pagos ao produtor de leite do Rio Grande do Sul de 1973 a 2007, bem como a evolução dos preços ao consumidor e da margem de comercialização. O estudo foi realizado com base nas séries históricas de preços nominais mensais de leite pagos ao produtor e pelos consumidores no Rio Grande do Sul, obtidas junto à EMATER/RS e ao IEPE/UFRGS, respectivamente. Os preços nominais foram deflacionados para dezembro de 2007 pelo IGP-DI da FGV. Calcularam-se os Índices de Preço ao Consumidor e ao Produtor, Índices de Estacionalidade, Relativos de Ciclo e Margens de Comercialização do produto. Observou-se que os preços pagos ao produtor apresentaram tendência de queda durante toda a série histórica. O mercado de leite apresentou ciclos históricos pouco regulares até o início da década de 1980, e a partir de 1987 observou-se forte tendência de mudança na trajetória dos índices de preço ao produtor e ao consumidor. A margem de comercialização do leite cresceu no período analisado, situando-se entre $27 \%$ e $69 \%$.
\end{abstract}

Termos para indexação: Bovinocultura de leite, margem de comercialização, preços agrícolas, séries temporais de preços.

\section{ABSTRACT}

The objective of this study is to analyse tendency behaviour, seasonality and price cycles of real prices paid to milk farmers in Rio Grande do Sul between 1973 and 2007, as well as the evolution of consumer prices and commercialization margins. The study was based on historical price series of nominal monthly milk prices paid to the producer and by consumers in Rio Grande do Sul, obtained through EMATER/RS and IEPE/UFRGS, respectively. The nominal prices were deflated for December 2007 according to the IGP-DI of the FGV. Consumer and farmer Price Indexes, Seasonal Indexes, relative cycles and product commercialization margins were calculated. It was observed that the prices paid to the farmer presented a decreasing tendency throughout the whole historical series. The milk market presented historical cycles generally regular until the beginning of the 1980s, and from 1987 on, a strong tendency toward change in farmer and consumer price indexes. The commercialization margin of milk increased during the period analysed, placing itself between $27 \%$ and $69 \%$.

Index terms: Agricultural prices, cattle milk, commercialization margin, time series.

\section{(Recebido em 13 de janeiro de 2009 e aprovado em 28 de julho de 2009)}

\section{INTRODUÇÃO}

A cadeia produtiva do leite no Rio Grande do Sul passou por um intenso processo de transformação nas últimas décadas. O setor leiteiro se rearticulou dentro de uma nova ótica liberalizante, fruto da abertura econômica e comercial brasileira ocorrida na década de 1990 do século passado.

Durante as décadas de 1970 e 1980, o Governo Federal desenvolvia políticas intervencionistas, tanto na produção leiteira, quanto em outros setores agrícolas. A intervenção do Estado na cadeia produtiva leiteira se dava principalmente por meio do tabelamento de preços do leite e de seus derivados (Silveira \& Pedrazzi, 2004). Nesse período, a indústria de laticínios do país era formada por pequenas e médias empresas e por um número reduzido de estabelecimentos do setor varejista. Predominava a existência de cooperativas e de empresas estatais, fomentadas por um governo que prezava a constituição de firmas de capital nacional.

Até o final da década de 1980, o Estado intervinha na cadeia produtiva do leite mediante regulação dos preços, tanto no que se refere aos preços finais, quanto aos pagos ao produtor. No elo industrial, a intervenção nos preços, aliada às características do leite pasteurizado, com sua pouca durabilidade e necessidade de refrigeração, resultava em amenização da concorrência entre as empresas. As cooperativas de produtores de leite e as empresas nacionais dominavam os mercados regionais de leite pasteurizado, ao passo que as transnacionais se inseriram em mercados

\footnotetext{
${ }^{1}$ Universidade Federal do Rio Grande do Sul/UFRGS - Rua João Alfredo, 312, Apt 531 - 90050-230 - Cidade Baixa - Porto Alegre, RS joaogaribaldi@brturbo.com.br

${ }^{2}$ Universidade Federal de Santa Maria/UFSM - Santa Maria, RS
} 
de outros derivados lácteos, como iogurte, leite longa vida, sobremesas lácteas, etc. (Figueira \& Belik, 1999).

Com a abertura econômica dos anos 90, o mercado passou a condicionar a dinâmica agrícola e o Estado reduziu o protecionismo em todos os setores. Nesse período, foi extinto o tabelamento de preços pela CIP (Comissão Interministerial do Preço) e iniciou-se um processo de concentração da indústria láctea. Para Castro et al. (1998), a política de tabelamento do preço do leite funcionava como um mecanismo inibidor à ação dos agentes empreendedores.

Com a reestruturação do setor, as cooperativas e empresas estatais passaram a ter um papel periférico na produção leiteira, e um intenso processo de modernização das técnicas e processos se iniciou, em razão do aumento da concorrência no mercado de leite e derivados. Essa nova dinâmica, aliada à implantação do Mercosul, gerou novos desafios para os produtores, principalmente para aqueles com pouca participação de mercado. Mais tarde, com o sucesso obtido pelo Plano Real na estabilização da economia, a partir de 1994 e o consequente aumento da renda real dos consumidores, elevou-se sucessivamente a demanda final de leite e o setor passou a ser atrativo para grandes investimentos.

Tais mudanças no ambiente institucional geraram maior concorrência entre as empresas inseridas no elo industrial, tanto no que se refere à captação de leite, quanto ao mercado de leite e derivados, propiciando um processo de fusões e aquisições - liderado pelas empresas privadas, principalmente as transnacionais - e desencadeando redução dos preços dos derivados lácteos que pressionou a redução dos preços em todos os elos da cadeia produtiva (Figueira \& Belik, 1999). No Rio Grande do Sul, onde, segundo Silveira \& Pedrazzi (2004), as propriedades com menos de 50 hectares produziram cerca de $84,3 \%$ da produção de leite, essas mudanças levaram a uma intensificação da produção, associada à expansão das bacias leiteiras e das indústrias de lácteos, principalmente na região Noroeste do Estado.

A concentração ocorrida no setor aliada à abertura econômica, à necessidade de redução de custos e melhoria de qualidade, observadas nos anos 1990, conduziram a uma concentração também no setor primário, com exclusão de pequenos produtores. Aparentemente, as indústrias competem por produtores que oferecem maiores volumes e leite de melhor qualidade, com pouco interesse em produtores com baixa escala produtiva, em decorrência de maiores custos de coleta, principalmente após a introdução da coleta a granel e refrigerada (Barros et al., 2004).
Esse conjunto de transformações setoriais afetou diretamente os mercados do leite, o que torna relevante o estudo do comportamento dos preços do produto nas últimas décadas, pois eles são tanto reflexos como também indutores de mudanças de conduta no setor. Assim, neste trabalho, objetivou-se analisar o comportamento dos preços reais pagos ao produtor de leite do Rio Grande do Sul de 1973 a 2007, enfatizando a evolução dos mesmos em termos de tendência, sazonalidade e ciclos. Além disso, pretende-se também analisar a evolução dos preços pagos pelo consumidor de leite e a margem de comercialização do produto, de forma a avaliar o reflexo do comportamento de tendência dos preços pagos ao produtor sobre o conjunto dos demais agentes da cadeia produtiva a jusante (atacado, indústria e varejo) e sobre o consumidor final.

\section{MATERIAL E MÉTODOS}

O presente trabalho foi realizado com base em duas séries históricas de preços nominais mensais do leite no Rio Grande do Sul (Anexo 1), de duas fontes diferentes: a) a série de preços médios pagos ao produtor de leite, coletadas pela EMATER/RS e disponibilizados para esta pesquisa por intermédio do Centro Integrado de Ensino, Pesquisa e Extensão Rural - CIEPER, convênio da EMATER/RS com a Universidade Federal de Santa Maria; e b) a série de preços médios pagos pelo consumidor final coletados pelo Centro de Estudos e Pesquisas Econômicas - IEPE da Universidade Federal do Rio Grande do Sul. Os dados mensais de preços pagos ao produtor e de preços pagos pelo consumidor abrangem o período de janeiro de 1973 a dezembro de 2007.

O itinerário metodológico partiu da atualização monetária dos preços, que passou pelas correções relativas aos diferentes planos econômicos (Cruzado, Verão, Collor e Real) e posterior deflacionamento, utilizando-se o Índice Geral de Preços (IGP-DI) na expressão 1, atualizando-os para valores reais equivalentes a dezembro de 2007:

$$
\mathrm{PRt}=(\mathrm{PNt} . \mathrm{IPa}) / \mathrm{IPt},
$$

onde:

$\mathrm{PRt}=$ preço real no mês " $\mathrm{t}$ ";

$\mathrm{PNt}=$ preço nominal corrigido no mês " $\mathrm{t}$ ";

IPa $=$ IGP-DI de dezembro de 2007;

IPt $=$ IGP-DI no mês " $\mathrm{t}$ ".

O cálculo dos Índices de Estacionalidade e dos Relativos de Ciclo seguiu a metodologia de análise de séries temporais preconizada por Kazmier (1982). O Índice de Estacionalidade foi calculado, utilizando-se o 
método das médias móveis de 13 meses que consiste, sucessivamente, em calcular a média móvel (média de treze meses consecutivos de preços) e a razão à média móvel (divisão de cada preço médio mensal pela respectiva média móvel centrada no mês, multiplicando o resultado por 100), determinar a média modificada de cada mês (média dos preços do mês após a eliminação dos valores mais alto e mais baixo), e calcular o Índice de Estacionalidade (multiplicação da média modificada por um fator de correção, de modo que a soma dos índices mensais, na qual o valor médio equivale a 100 , seja 1.200).

Para calcular os Relativos de Ciclo, foi necessário ajustar uma reta de regressão aos dados de preços reais pagos ao produtor, de forma a estimar valores de tendência para cada período de tempo. Tal reta foi ajustada utilizandose o método dos mínimos quadrados, conforme Johnston (1977), tendo como variável dependente o preço real médio anual desestacionalizado (conforme a expressão 3) e como variável independente o período de tempo, operacionalizada, esta última, como uma sequência numérica que representa cada um dos anos analisados (1, $2,3,4,5 \ldots 35$, no caso da série completa de preços pagos ao produtor). Pela regressão, estimaram-se os parâmetros "a" e "b" da expressão 2:

$$
\mathrm{PT}=\mathrm{a}+\mathrm{b} . \mathrm{T},
$$

onde:

$\mathrm{PT}=$ preço de tendência;

$\mathrm{a}=$ coeficiente linear da reta de tendência;

$\mathrm{b}=$ coeficiente angular da reta de tendência;

$\mathrm{T}=$ período de tempo $(1,2,3,4,5 \ldots 35)$.

$$
\mathrm{PDt}=(\mathrm{PRt} / \mathrm{IEt}) .100,
$$

onde:

PDt = preço real desestacionalizado no mês " $t$ ";

$\mathrm{PRt}=$ preço real no mês " $\mathrm{t}$ ";

$\mathrm{IEt}=$ Índice de Estacionalidade do mês " $\mathrm{t}$ ".

Depois de realizada a regressão, os Relativos de Ciclo foram calculados dividindo-se o valor observado (o preço médio anual desestacionalizado) pelo respectivo valor estimado por meio da equação de regressão para cada ano (preço de tendência) e multiplicando-se o resultado por 100 , conforme a expressão 4 :

$$
\text { R.C. }=(\mathrm{PDt} / \mathrm{PTt}) \cdot 100 \text {, }
$$

onde:

R.C. = Relativo de Ciclo;

$\mathrm{PDt}=$ preço real desestacionalizado no ano " $\mathrm{t}$ ";

$\mathrm{PTt}=$ preço de tendência no ano " $\mathrm{t}$ ".

Para cada uma das séries de preços analisadas, foi também calculado o Índice de Preço, baseados nos preços reais médios anuais, com a base 100 em 1973, conforme apresentados na Figura 5. O Índice de Preço, na medida em que transforma valores absolutos (em unidades monetárias) em valores relativos (sem unidade alguma) fixados em uma mesma base, permite que se possa comparar a evolução dos dois preços. Além disso, para permitir avaliar os períodos de maior e menor variação de preços, calculouse a taxa média geométrica de variação anual dos índices de preço ao produtor, por meio da expressão 5, conforme Crusius \& Assis (1992):

$$
\mathrm{Tx}=\left\{\left[(\mathrm{IPn} / \mathrm{IPo})^{1 / \mathrm{n}}\right]-1\right\} .100,
$$

onde:

Tx = taxa média geométrica de variação por período;

IPn = índice de preço do final do período;

IPo = índice de preço do início do período;

$\mathrm{n}=$ número de anos do período.

Por fim, calculou-se a Margem de Comercialização Relativa Total (expressão 6) com base em Barros (1987). Essa margem, representa o valor percentual do preço do leite ao consumidor que é apropriado pelos setores a jusante do produtor (indústria, atacado e varejo). Ou seja, é a percentagem do preço ao consumidor que não é repassada ao produtor:

$$
\mathrm{MRt}=[(\mathrm{PRtC}-\mathrm{PRtP}) / \mathrm{PRtC}] .100,
$$

onde: MRt = Margem de Comercialização Relativa Total no ano "t"; $P R t C=$ Preço real ao consumidor no ano " $t$ "; $\mathrm{PRtP}=$ Preço real ao produtor no ano " $\mathrm{t}$ ".

Poder-se-á observar na exposição dos resultados, que algumas análises foram feitas partindo-se a série histórica em 1994, para captar alterações decorrentes da estabilização monetária da economia.

\section{RESULTADOS E DISCUSSÃO}

\section{Trajetória dos preços reais ao produtor}

Os preços pagos ao produtor de leite do Rio Grande do Sul têm apresentado uma tendência de queda desde a década de 1970, configurando uma taxa média geométrica 
de crescimento de $-2,45 \%$ ao ano. A tendência de declínio de preços foi acentuada a partir da década de 1980, se estendendo até a década de 1990, a qual esboçou as taxas médias geométricas de crescimento mais negativas de todo o período (-6,34\% ao ano), e amainou a partir dos anos 2000. A partir do Plano Real, as taxas continuaram negativas, porém em nível inferior à média das décadas de 1970 e 1980 em razão da estabilidade monetária alcançada.

A queda acentuada dos preços pagos ao produtor do Rio Grande do Sul acompanhou o aumento significativo da produção de leite no mesmo período no Brasil, que segundo Food Agricultural Organization-FAO (2008) cresceu de 7,7 bilhões de litros produzidos em 1973 para 25,3 bilhões de litros de leite em 2007, ou seja, um crescimento de produção de 228,5\%. Observando-se toda a série histórica de preços do Rio Grande do Sul (Figura 1), constata-se que 2006 foi o ano de menor preço pago ao produtor, com média anual de $\mathrm{R} \$ 0,43$ por litro de leite, seguido pelo ano de 2002, com preços médios anuais ao redor de R \$ 0,44 por litro. Os maiores preços pagos ao produtor foram praticados na década de 1970 , tendo como ápice o ano de 1975 com $\mathrm{R} \$ 1,79$ por litro de leite.

Constata-se que os preços pós Plano Real (1995 a 2007) têm oscilado, sem que haja tendência visível, em torno de um valor médio de R \$ 0,51 por litro, o qual, acredita-se, seja um preço de equilíbrio para o período. Entretanto, ao observar os preços praticados no primeiro semestre de 2008, verifica-se a alta dos preços do leite, alcançando o patamar de R \$ 0,64. Essa elevação ocorreu, em razão do aumento da demanda de lácteos em relação à oferta, tanto no mercado interno, como no mercado externo na safra 2007/2008.

\section{Ciclos e sazonalidade dos preços pagos ao produtor}

$\mathrm{Na}$ Figura 2, apresentam-se os chamados "Relativos de Ciclo" dos preços pagos ao produtor, ou seja, a variação percentual dos desvios do preço real em relação ao preço de tendência apresentados na Figura 1. O mercado de leite apresenta ciclos históricos mais ou menos regulares até o início da década de 1980, não ultrapassando três anos sem que se inverta a trajetória de curto prazo dos preços, de alta ou de baixa.

A partir de 1982, não foi mais possível identificar a presença de ciclos regulares, o que demonstra que a dinâmica de mercado que é observada em outros produtos agrícolas, de expansão da atividade em momentos de alta e de retração em momentos de baixa de preço, não pode ser observada nos preços do leite. Essa ausência de ciclos torna difícil para o produtor precaver-se contra momentos de crise, pois essa previsão já não é mais possível, em contraste com outras atividades agrícolas que possuem ciclos regulares.

Na Figura 3, apresenta-se a variação estacional (sazonalidade) dos preços pagos ao produtor (Anexo 2) a variação média de preços dentro do ano - o que é representado pelo chamado "Índice de Estacionalidade", por meio do qual se pode visualizar a amplitude das oscilações em torno do índice médio 100.

Como a variação estacional dos produtos agrícolas pode modificar-se com o tempo, seja em função de fatores produtivos ou mercadológicos, calculou-se o índice médio de estacionalidade de 1973 a 1994 e 1995 a 2007. Por meio dele, pôde-se observar que a variação estacional do leite apresentou certa homogeneidade de comportamento.

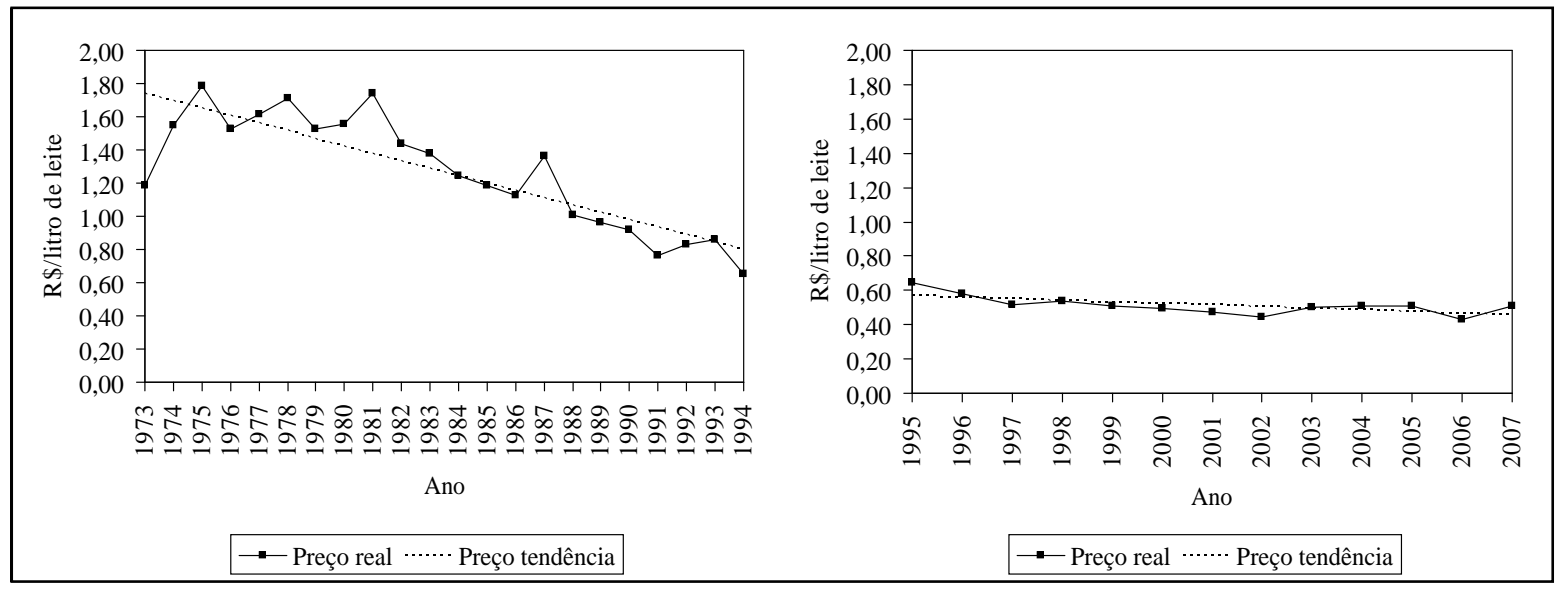

Figura 1 - Tendência e preço real do leite ao produtor no Rio Grande do Sul de 1973 a 1994 e 1995 a 2007. 


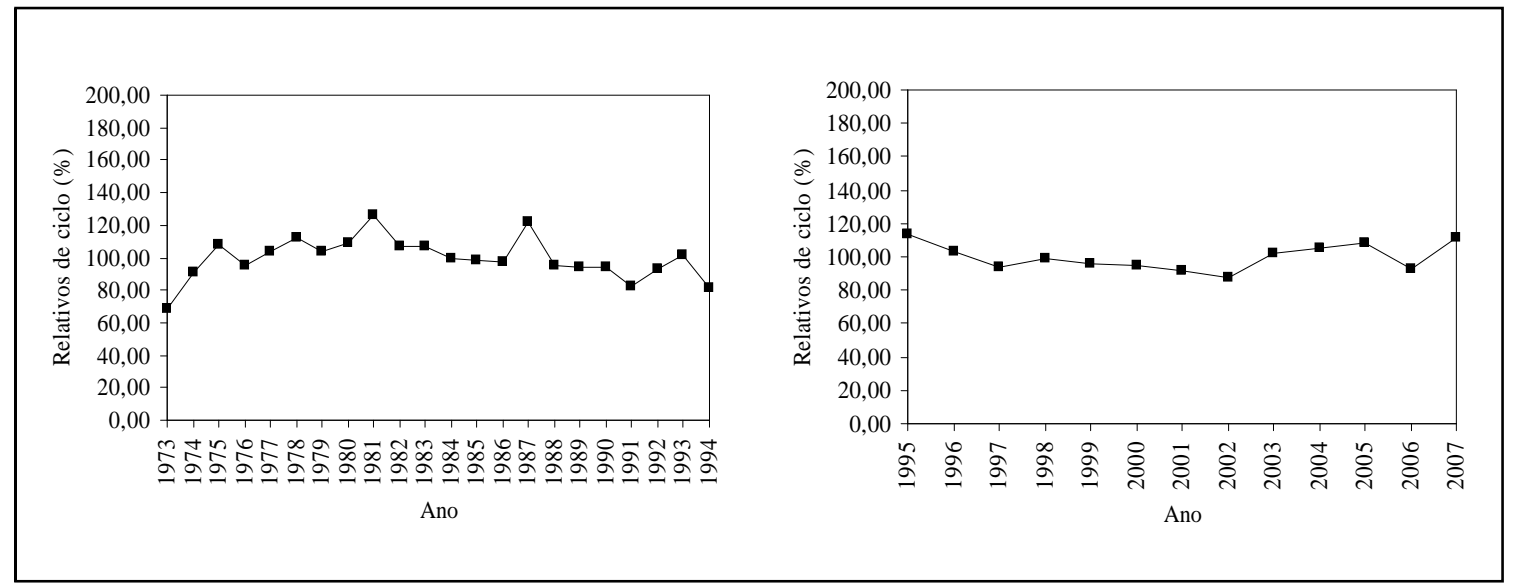

Figura 2 - Relativos de Ciclo do preço do leite ao produtor no Rio Grande do Sul de 1973 a 1994 e 1995 a 2007.

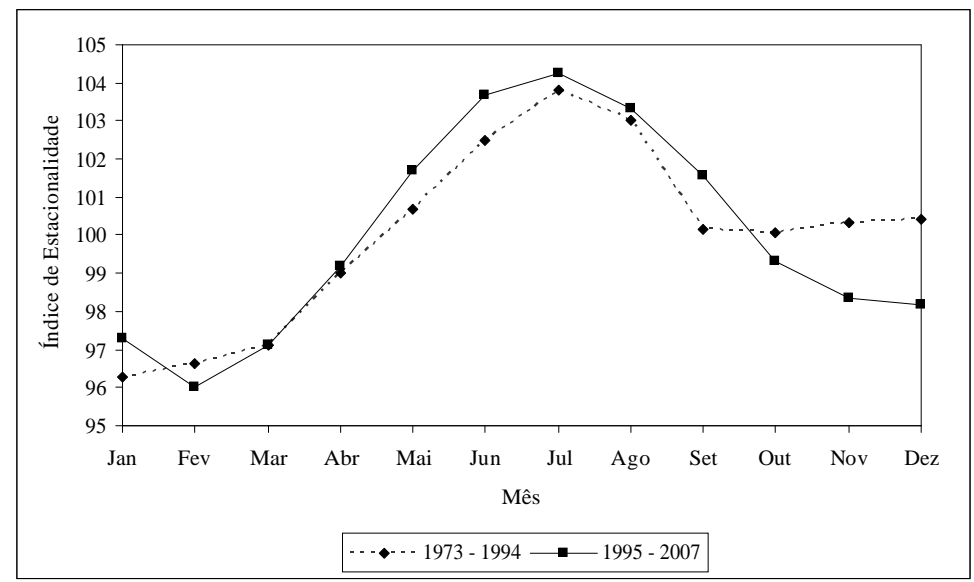

Figura 3 - Variação estacional dos preços do leite ao produtor do Rio Grande do Sul de 1973 a 1994 e 1995 a 2007.

Verificou-se um aumento na sazonalidade dos preços do leite a partir de 1995, em razão da abertura comercial do país e à diminuição significativa do controle governamental sobre os preços (preços mínimos, AGF, EGF), fator este que amainava a sazonalidade de preços nas décadas de 1970 e 1980.

No período de 1973 a 1990, em função de o leite representar uma parcela significativa no custo da cesta básica do consumidor, o mercado do produto era regido pelo Governo Federal, por meio de políticas protecionistas e de preços. Nesse período, os maiores preços ao produtor encontravam-se no período de entressafra, mais precisamente no mês de julho, período de menor oferta de leite, em razão da restrição alimentar da estação de inverno, e os menores preços eram praticados no período de safra, no mês de janeiro, período de alta produção leiteira. No período pós Plano Real, a maior abertura comercial do Brasil, sobretudo para países vizinhos do Mercosul, trouxe uma maior instabilidade aos mercados. Assim, a sazonalidade dos preços do leite aumentou, porém persistiu o comportamento sazonal, no qual os maiores preços pagos ao produtor encontram-se nos meses de inverno (entressafra), enquanto os menores preços são praticados nos meses de safra de janeiro e fevereiro.

\section{Evolução dos preços ao produtor e ao consumidor de leite do Rio Grande do Sul}

Quando se observa a tendência declinante dos preços pagos ao produtor, uma questão vem à tona: quem tem se beneficiado do fenômeno de queda de preços no longo prazo, ou para quem está sendo transferida a renda do setor lácteo decorrente da persistente queda? 
Levando-se em conta que a tendência de preços dos produtos agrícolas, principalmente daqueles que têm uma participação maior na cesta básica do consumidor, é de queda significativa ao longo dos anos, foram analisadas as séries dos preços reais pagos ao produtor e ao consumidor.

Ao observar-se a Figura 4, evidencia-se a similaridade do comportamento de preços entre as duas séries históricas. Apesar da desvalorização significativa dos preços do leite, as oscilações nos preços pagos aos produtores acompanharam as variações de preços em nível de consumidor.

Quanto maior o deslocamento entre as duas séries apresentadas na Figura 4, maior será a margem de comercialização do produto, que representa o quanto o setor a jusante (atacado, varejo, indústria) está se apropriando dos preços pagos pelos consumidores.

Na Figura 5, apresenta-se a evolução dos índices de preços ao produtor e ao consumidor, ambos com base $100 \mathrm{em}$ 1973. Conforme os índices que representam a evolução da variação dos preços a partir de uma base comum, foi possível observar que, até o início da década de 1990 , os preços ao produtor e ao consumidor tiveram um comportamento semelhante, apresentando pequenas variações. Até o ano de 1987, o índice de preço ao produtor era maior que o índice de preço ao consumidor, demonstrando que a margem de comercialização mantinhase constante.

A partir de 1987 houve uma mudança nas trajetórias dos índices de preços, fazendo com que as persistentes quedas dos preços ao produtor causassem a elevação da margem de comercialização do leite, provavelmente, em razão da abertura comercial e à formação de oligopólios industriais, que passaram a estabelecer preços e rentabilidade.

Na Figura 6, apresenta-se a evolução da margem de comercialização do leite a partir de 1973. A margem de comercialização elevou-se significativamente a partir de 1987 e atingiu o pico máximo em 2000, com valor em torno de $69 \%$. A partir de 2003, a margem de comercialização do leite apresentou um breve declínio, em razão do aumento do preço pago ao produtor. O valor mínimo foi alcançado em 1978, com margem de comercialização em torno de $27 \%$. Portanto, a variação das margens de comercialização do leite situa-se entre $27 \%$ e $69 \%$, com crescimento acentuado durante a década de 1990.

O aumento da margem de comercialização acompanhou a mudança estrutural e conjuntural do setor lácteo. A partir da queda gradativa da proteção governamental ao setor e a abertura econômica e comercial do país, constituiu-se a concentração de agroindústrias processadoras, bem como um aumento da distribuição do produto leite nas grandes redes varejistas. Dessa forma, os elos mais próximos ao consumidor têm se apropriado da maior parcela paga pelo produto leite no varejo. $\mathrm{Na}$ visão de Barros et al. (2004), do ponto de vista do consumidor, o desempenho do setor lácteo tem sido satisfatório em razão da demanda ter sido atendida a preços decrescentes. Ou seja, a evolução do mercado de leite no Rio Grande do Sul trouxe benefícios para os consumidores finais. Entretanto, os produtores de leite cada vez mais se tornam dependentes da indústria, com menor poder de decisão ao longo da cadeia produtiva e recebendo uma parcela decrescente do valor do produto final.

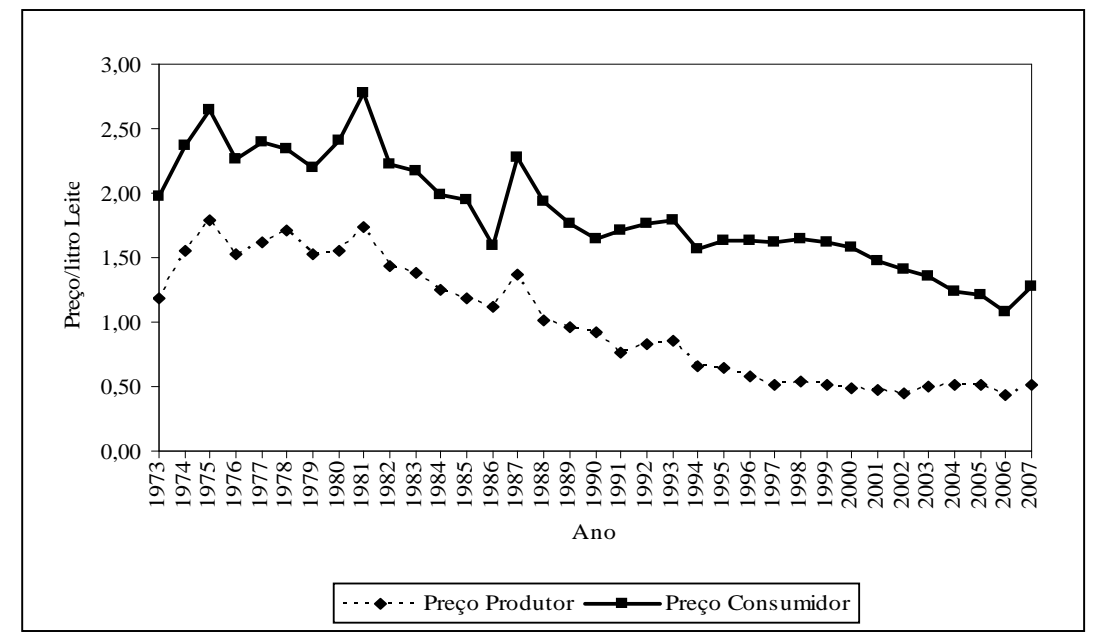

Figura 4 - Preços reais do leite ao produtor e ao consumidor no Rio Grande do Sul de 1973 a 2007. 


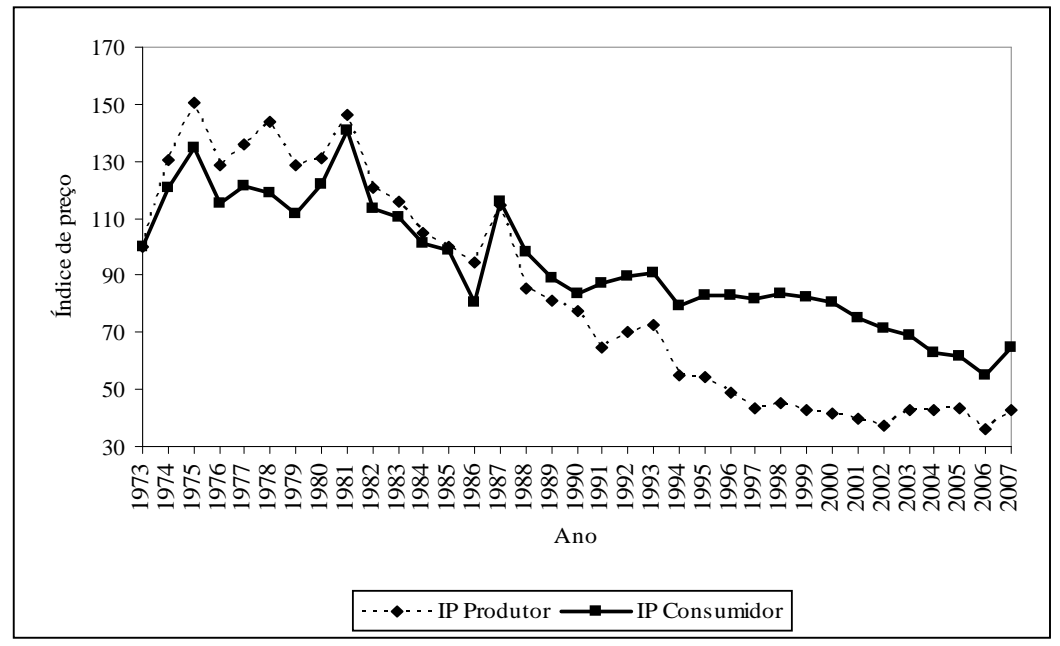

Figura 5 - Índices de preço do leite ao produtor e ao consumidor no Rio Grande do Sul (base $100=1973$ ).

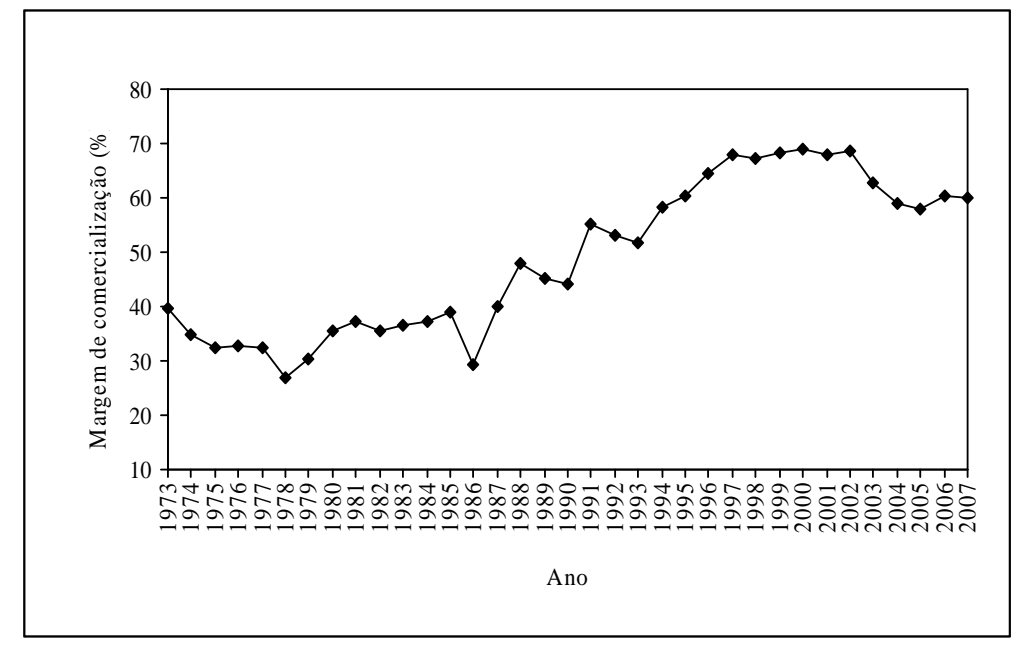

Figura 6 - Margem de comercialização do leite no Rio Grande do Sul de 1973 a 2007.

O crescimento da margem de comercialização está atrelado às mudanças conjunturais da década de 1990 que estimularam a consolidação de oligopsônios concorrenciais na cadeia do leite do Rio Grande do Sul (Breitenbach, 2008). Os oligopsônios determinam os preços e estabelecem as principais estratégias e inovações tecnológicas do setor, fazendo com que se apropriem de uma maior parcela do valor pago pelo consumidor.

\section{CONCLUSÕES}

Os preços pagos ao produtor de leite no Rio Grande do Sul apresentaram uma forte tendência de queda ao longo de toda a série histórica analisada. Essa tendência de queda dos preços do produtor foi acompanhada de comportamento similar pelos preços ao consumidor até o início da década de 1990. A partir desse período, os preços ao produtor apresentaram queda mais acentuada e os setores a jusante (atacado, varejo, indústria) apropriaramse da maior parcela do valor pago pelo consumidor, aumento observado pela margem de comercialização.

Observou-se que até o início da década de 1980 os preços pagos ao produtor apresentaram ciclos regulares de três anos, entretanto, a partir dessa data não foi possível identificar a presença de ciclos regulares. A sazonalidade dos preços pagos ao produtor elevou-se ligeiramente a partir da década de 1990, em consequência da abertura 
econômica e comercial do país e da diminuição gradativa da intervenção governamental no setor. Porém, a elevação da sazonalidade não foi intensa, mantendo-se os períodos de safra e entressafra com os de maior e menor preço durante ao ano, respectivamente.

\section{REFERÊNCIAS BIBLIOGRÁFICAS}

BARROS, G.S.C. Economia da comercialização agrícola. Piracicaba: FEALQ, 1987. 306p.

BARROS, G.S.C.; SBRISSIA, G.F.; SPOLADOR, H.F.S.; PONCHIO, L.A. Mudanças estruturais na cadeia do leite: reflexos sobre os preços. Revista de Política Agrícola, ano 8, n.3, p.13-26, 2004.

BREITENBACH, R. Estruturas de mercado de fatores e governança da cadeia produtiva do leite: um estudo de caso do município de Ajuricaba - RS. 2008. 114f.

Dissertação (Mestrado em Extensão Rural)-Universidade Federal de Santa Maria, Santa Maria, 2008.

CASTRO, C.C. de; PADULA, A.D.; MATTUELLA, J.L.; MULLER, L.A.; ANGST, A.N. Estudo da cadeia láctea do Rio Grande do Sul: uma abordagem das relações entre os elos da produção, industrialização e distribuição. Revista de Administração Contemporânea, Curitiba, v.2, n.1, p.143-164, 1998.

CRUSIUS, C.; ASSIS, A.L. de. Cálculos com índices: índices, fatores e taxas. Porto Alegre: GECE/FCE/UFRGS, 2002. (Série Manuais GECE, 1).

FIGUEIRA, S.R.; BELIK, W. Transformações no elo industrial da cadeia produtiva do leite. Cadernos de Debate, São Paulo, v.7, p.31-44, 1999.

FOOD AGRICULTURAL ORGANIZATION. Estatísticas. Disponível em: $\langle$ htttp://faostat.fao.org set. 2008.

JOHNSTON, J. Métodos econométricos. São Paulo: Atlas, 1977. 313p.

KAZMIER, L.J. Estatística aplicada à economia e administração. São Paulo: McGraw-Hill, 1982. 376p.

SILVEIRA, V.C.P.; PEDRAZZI, P.R. As transformações na cadeia produtiva do leite: impactos no Rio Grande do Sul e em Santa Maria. Santa Maria: UFSM, 2004. Disponivel em: $<\mathrm{htt}$ ://www.ufsm.br/cieper/mainfilesh ResumoCPILeite2.doci P. Acesso em: 8 ago. 2008 . 


\section{ANEXOS}

Anexo 1 - Indicadores de tendência, ciclos de preços e margens de comercialização do leite no Rio Grande do Sul de 1973 a 2007.

\begin{tabular}{|c|c|c|c|c|c|c|}
\hline $\begin{array}{c}\text { Produto } \\
\text { Ano }\end{array}$ & $\begin{array}{c}\text { Preço real ao } \\
\text { produtor } \\
(\mathrm{R} \$ / \text { Litro })\end{array}$ & $\begin{array}{l}\text { Preço real ao } \\
\text { consumidor } \\
(\mathrm{R} \$ / \mathrm{Litro})\end{array}$ & $\begin{array}{c}\text { IP ao } \\
\text { produtor }\end{array}$ & $\begin{array}{c}\text { IP ao } \\
\text { consumidor }\end{array}$ & $\begin{array}{l}\text { Relativos de } \\
\text { Ciclo }(\%)\end{array}$ & $\begin{array}{c}\text { Margens de } \\
\text { Comercialização } \\
(\%)\end{array}$ \\
\hline 1973 & 1,19 & 1,97 & 100 & 100 & 68,27 & 39,63 \\
\hline 1974 & 1,55 & 2,38 & 130,38 & 120,68 & 91,41 & 34,82 \\
\hline 1975 & 1,79 & 2,65 & 150,35 & 134,54 & 108,39 & 32,53 \\
\hline 1976 & 1,53 & 2,27 & 128,57 & 115,19 & 95,31 & 32,64 \\
\hline 1977 & 1,61 & 2,39 & 135,87 & 121,47 & 103,42 & 32,47 \\
\hline 1978 & 1,71 & 2,34 & 143,82 & 118,76 & 112,76 & 26,91 \\
\hline 1979 & 1,53 & 2,19 & 128,49 & 111,51 & 103,88 & 30,45 \\
\hline 1980 & 1,55 & 2,40 & 130,77 & 122,18 & 108,89 & 35,40 \\
\hline 1081 & 1,74 & 2,78 & 146,44 & 141,08 & 125,80 & 37,36 \\
\hline 1982 & 1,44 & 2,23 & 120,86 & 113,26 & 107,42 & 35,62 \\
\hline 1983 & 1,38 & 2,17 & 115,9 & 110,28 & 106,58 & 36,59 \\
\hline 1984 & 1,25 & 1,99 & 104,79 & 100,93 & 99,90 & 37,31 \\
\hline 1985 & 1,19 & 1,94 & 99,82 & 98,66 & 98,68 & 38,90 \\
\hline 1986 & 1,12 & 1,59 & 94,6 & 80,78 & 97,10 & 29,26 \\
\hline 1987 & 1,36 & 2,28 & 114,88 & 115,68 & 122,37 & 40,07 \\
\hline 1988 & 1,01 & 1,94 & 85,15 & 98,43 & 94,68 & 47,81 \\
\hline 1989 & 0,96 & 1,76 & 80,9 & 89,31 & 93,98 & 45,30 \\
\hline 1990 & 0,92 & 1,65 & 77,53 & 83,65 & 94,20 & 44,05 \\
\hline 1991 & 0,77 & 1,71 & 64,54 & 87,13 & 82,07 & 55,31 \\
\hline 1992 & 0,83 & 1,77 & 69,97 & 89,93 & 93,33 & 53,02 \\
\hline 1993 & 0,86 & 1,79 & 72,39 & 90,8 & 101,77 & 51,87 \\
\hline 1994 & 0,65 & 1,57 & 54,92 & 79,52 & 81,52 & 58,34 \\
\hline 1995 & 0,64 & 1,63 & 54,25 & 82,73 & 113,24 & 60,44 \\
\hline 1996 & 0,58 & 1,63 & 48,82 & 82,74 & 103,59 & 64,37 \\
\hline 1997 & 0,52 & 1,61 & 43,57 & 81,91 & 94,06 & 67,93 \\
\hline 1998 & 0,54 & 1,65 & 45,31 & 83,76 & 99,35 & 67,35 \\
\hline 1999 & 0,51 & 1,62 & 42,99 & 82,27 & 96,04 & 68,44 \\
\hline 2000 & 0,49 & 1,58 & 41,5 & 80,39 & 94,43 & 68,84 \\
\hline 2001 & 0,47 & 1,47 & 39,7 & 74,94 & 91,94 & 67,98 \\
\hline 2002 & 0,44 & 1,41 & 37,12 & 71,46 & 87,61 & 68,63 \\
\hline 2003 & 0,51 & 1,36 & 42,49 & 69,12 & 102,12 & 62,87 \\
\hline 2004 & 0,51 & 1,24 & 43,08 & 63,1 & 105,66 & 58,87 \\
\hline 2005 & 0,51 & 1,21 & 43,18 & 61,63 & 107,93 & 57,85 \\
\hline 2006 & 0,43 & 1,08 & 36,27 & 54,77 & 92,61 & 60,19 \\
\hline 2007 & 0,51 & 1,27 & 42,95 & 64,75 & 111,71 & 59,84 \\
\hline
\end{tabular}

Fonte: elaborado pelos autores a partir de dados primários da EMATER/RS e do IEPE/UFRGS.

IP: Índice de Preços. 
VIANA, J. G. A. et al.

Anexo 2 - Índices de Estacionalidade dos preços pagos ao produtor de leite do Rio Grande do Sul por período.

\begin{tabular}{|c|c|c|c|c|}
\hline $\begin{array}{c}\text { Período } \\
\text { Mês }\end{array}$ & Década de 70 & Década de 80 & Década de 90 & $1995-2007$ \\
\hline Janeiro & 102,52 & 94,41 & 95,84 & 97,28 \\
\hline Fevereiro & 100,32 & 94,62 & 94,88 & 96,03 \\
\hline Março & 98,64 & 95,64 & 96,08 & 97,14 \\
\hline Abril & 93,94 & 99,66 & 99,74 & 99,2 \\
\hline Maio & 97,96 & 101,61 & 100,47 & 101,7 \\
\hline Junho & 98,90 & 102,90 & 105,01 & 103,69 \\
\hline Julho & 100,41 & 107,38 & 104,98 & 104,25 \\
\hline Agosto & 100,09 & 106,29 & 104,34 & 103,33 \\
\hline Setembro & 100,65 & 100,24 & 102,30 & 101,56 \\
\hline Outubro & 100,38 & 100,56 & 99,30 & 99,32 \\
\hline Novembro & 102,71 & 100,71 & 97,84 & 98,33 \\
\hline Dezembro & 103,47 & 95,97 & 99,23 & 98,17 \\
\hline
\end{tabular}

Fonte: elaborado pelos autores a partir de dados primários da EMATER/RS e do IEPE/UFRGS. 